\title{
PERFORMANCE OF PRE-CHLORINATION, COAGULATION AND ADSORPTION FOR CONTROLLING THE FORMATION OF CARCINOGENIC COMPOUND IN TREATED WATER
}

\author{
Euis Nurul Hidayah", Fauzul Rizqa and Okik Hendriyanto Cahyonugroho \\ Department of Environmental Engineering, University of Pembangunan Nasional "Veteran" \\ Jawa Timur, 60294, Indonesia \\ *E-mail: euisnh.tl@upnjatim.ac.id
}

\begin{abstract}
Aquatic organic matters refer to chemical compounds that result from natural processes in the environmental including algae metabolic reactions and decomposition of organic matter. The removal of NOM is the most effective effort to minimize the generation of disinfection by-products (DBPs). Aims of this research are to compare various treatments in controlling aquatic organic matters, which caused the formation of the carcinogenic compound. Combination processes of pre-chlorination, coagulation with alum and $\mathrm{FeCl}_{3}$ and adsorption with powdered activated carbon (PAC) was applied under different dosage. TOC and $\mathrm{UV}_{254}$ were measured to quantify organic matters, Fourier Transform Infrared (FTIR) was applied to identify organics properties, and $\mathrm{CHCl}_{3}$ was measured to know carcinogenic concentration. The results showed that pre-chlorination only caused the formation of lower molecular weight, pre-chlorination followed by coagulation combined with adsorption showed a better result than coagulation-adsorption only. $\mathrm{FeCl}_{3}$ coagulant is more effective than alum. Aromatic compounds are a precursor for the formation of $\mathrm{CHCl}_{3}$, since removal $\mathrm{UV}_{254}$ along with $\mathrm{CHCl}_{3}$ concentration.
\end{abstract}

Keywords: Organic matters, Pre-Chlorination, Coagulation, Adsorption, Chloroform

○ RASĀYAN. All rights reserved

\section{INTRODUCTION}

Disinfection has an important role in avoiding the broaden of waterborne diseases. Disinfectants are productive in inactivating deleterious microorganisms, disinfectants are very reactive with organic and inorganic materials in treated water as well and leading to the formation of DBPs. ${ }^{1}$ It has been known that DBPs are highly toxic and adverse human health effects. ${ }^{2}$ One method for controlling and minimizing the formation of DBPs is the removal of natural organic matter (NOM). NOM is a mixture of heterogeneous natural organic compounds that exist in water especially surface water. ${ }^{3,4}$ The presence of NOM in waters can cause negative effects on raw water quality such as color, odor, and taste ${ }^{5}$, caused membrane fouling ${ }^{6}$, thus forming disinfection by-products (DBPs) such as trihalomethanes (THMs), haloacetic acids (HAAs), haloketones, haloacetonitriles, haloaldehydes, and halogenated furanones. ${ }^{7}$ The formation of DBPs is affected by the characteristics of NOM such as ultraviolet absorbance, aromatic/aliphatic content, and carboxylic/phenolic acidity. In drinking water treatment plant, enhanced coagulation could remove hydrophobic, aromatic, phenol, conjugated double bond, and degrade high molecular weight (HMW) of $\mathrm{NOM}^{5,8}$ whereas PAC adsorption is used to remove low molecular weight (LMW) and cause odor in raw water. ${ }^{9}$ Basically, all treatment processes have different capability to remove organic compounds, and treatment efficiency depends on the characteristics and properties of organic compounds. In addition, it has been developed some numbers of organic matter characterization, for example: using bulk parameters for quantitative analysis in terms of total organic carbon (TOC), ultraviolet at $254 \mathrm{~nm}\left(\mathrm{UV}_{254}\right)$. Another is qualitative methods, which is fractioned organic matter based on their properties, for example: using chromatography, fluorescence, spectrophotometer, etc. According to those information, therefore the objectives of this study is compare various treatment, including pre-chlorination, coagulation, adsorption

Rasayan J. Chem., 12(4), 2111-2115(2019)

http://dx.doi.org/10.31788/RJC.2019.1245472

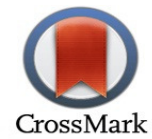


under different dosage and materials, for controlling the formation of carcinogenic compounds in treated water. This research will help with water treatment regarding the effect of organic matter existence in water, and a chance to be applied in wastewater treatment as well.

\section{EXPERIMENTAL}

Water samples were carried out from the outlet of the pre-sedimentation chamber at a water treatment plant in Surabaya, Indonesia. Experimental was divided into eleven (11) various treatment processes, including pre-chlorination, coagulation, adsorption. All of these processes were done by using the jar test (Phipps \& Bird PB-700). $20 \mathrm{ppm} \mathrm{CaOCl}_{2}$ as an oxidant in pre-chlorination was added into the jar contain water sample and mixing $110 \mathrm{rpm}$ for $20 \mathrm{~min}$. Next, $90 \mathrm{ppm} \mathrm{Al} \mathrm{Al}_{2}\left(\mathrm{SO}_{4}\right)_{3}$ as coagulant was mixing fast at $110 \mathrm{rpm}$ for 30 seconds, slow mixing $25 \mathrm{rpm}$ for $30 \mathrm{~min}$, and settling for $15 \mathrm{~min}$. PAC has added $10 \mathrm{ppm}$ or $40 \mathrm{ppm}$ and mix under $110 \mathrm{rpm}$ for $30 \mathrm{~min}$. Samples were filtered by using $0.45 \mu \mathrm{m}$ cellulose acetate (CA) filtered paper before chloroform analysis, functional groups FTIR measurements, TOC, and $\mathrm{UV}_{254}$ value. Chloroform $\left(\mathrm{CHCl}_{3}\right)$ one of the species trihalomethanes was measured by purge and trap packed column gas chromatographic method (Model 3400 GC, Varian, USA) equipped with a purge and trap module (Model LCS-2000, Tekmar, USA). ${ }^{10}$ This study concerned about $\mathrm{CHCl}_{3}$ due to this species exists in pre-chlorinated water in high concentration. FTIR spectroscopy (Thermo Nicolet NEXUS 670) with wavelengths $4000-400 \mathrm{~cm}^{-1}$ was used to identify functional groups of organic matters. ${ }^{11}$ The TOC measurement was analyzed using Shimadzu TOC analyzer, and $\mathrm{UV}_{254}$ was measured by UV/vis spectrophotometer (Agilent 8453). ${ }^{12}$

\section{Characteristics of Raw Water}

\section{RESULTS AND DISCUSSION}

The raw water from effluent prasedimentation plant had a very high TOC concentration, about 9.645 $\mathrm{mg} / \mathrm{L}$ as high as $\mathrm{UV}_{254}$. The high TOC concentration indicated high organic matters compound, it could be as aromatic, non-aromatic compound, humic-like and non-humic substances-like compound, soluble microbial products, etc. ${ }^{7}$ According to $\mathrm{UV}_{254}$ value, it presented high aromatic compound in the effluent of pre-sedimentation process. Raw water from the effluent of pre-sedimentation still contain high organic matters, it is probably due to raw water from surface water was contaminated from human activities, such as from domestic and industrial wastewater discharged into surface water. ${ }^{5}$ It seems that organic matter concentration in raw water could not be removed in physical treatment, such as in pre-sedimentation. ${ }^{3}$ The raw water also has high turbidity due to the rainfall experienced prior to sampling, and neutral $\mathrm{pH}^{10}$. The characteristics of organic matter in raw water are presented in Table-1.

Table-1: Characteristics of raw water

\begin{tabular}{l|c|c|c|c}
\hline Sample & $\mathrm{pH}$ & Turbidity (NTU) & TOC $(\mathrm{mg} / \mathrm{l})$ & $\mathrm{UV}_{254}\left(\mathrm{~cm}^{-1}\right)$ \\
\hline Raw water & 7.51 & 65.9 & 9.645 & 0.077 \\
\hline
\end{tabular}

Comparison Between $\mathrm{CHCl}_{3}$ Removal and Organic Matters Removal in Various Treatments

Carcinogenic compounds are represented as $\mathrm{CHCl}_{3}$ or chloroform, one of the species of trihalomethanes (THMs), and it is known as disinfectant by-products (DBPs). Organic matters, mostly represented as TOC concentration and $\mathrm{UV}_{254}$ value parameters, are precursors for disinfectant by-products (DBPs) generation. ${ }^{13}$ Comparison between $\mathrm{CHCl}_{3}$ and organic matter removal could describe the effect of organic matters on the formation of $\mathrm{CHCl}_{3}$. Figure-1 shown removal TOC and $\mathrm{UV}_{254}$ compare with $\mathrm{CHCl}_{3}$ removal in all treatment processes. Firstly, it shows that $\mathrm{UV}_{254}$ removal is higher than TOC removal. It indicated that aromatic compounds are more amenable removed during water treatment processes through coagulation and adsorption. Aromatic compounds contain a humic substances-like compounds and it is more hydrophobic and easy to be removed. ${ }^{3,10}$ Secondly, the removal of carcinogenic $\mathrm{CHCl}_{3}$ shows a higher removal along with $\mathrm{UV}_{254}$ removal. It seems that aromatic compounds are organic precursors of $\mathrm{CHCl}_{3}$ formation. This result shows consistency with previous studies. ${ }^{3,11-14}$ Third, treatment comparison between coagulant combined with PAC presented that alum shows a higher removal (about 85\%) of $\mathrm{CHCl}_{3}$ concentration than $\mathrm{FeCl}_{3}$. However, the $\mathrm{FeCl}_{3}$ coagulant showed its effectiveness in removing 
almost $40 \%$ organic aromatic compounds, as shown in the $\mathrm{UV}_{254}$ value. Both coagulants have a similar capability to remove organic matter in terms of TOC concentration, about $20-25 \%$.

Further, treatment comparison under pre-chlorination indicated that pre-chlorination could help to enhance organic matter removal. The results show a combination of pre-chlorination-coagulant-activated carbon resulted in a higher removal for all parameters than others. As shown in Fig.-1, alum coagulant performed better efficiency than $\mathrm{FeCl}_{3}$, about $90 \%, 60 \%$ and $40 \%$ removal of $\mathrm{CHCl}_{3}$ concentration, $\mathrm{UV}_{254}$ value, and TOC concentration, respectively. It seems that if pre-chlorination is applied as pretreatment and activated carbon as post-treatment, then alum is a suitable coagulant for removing organic matter in order to control the formation of $\mathrm{CHCl}_{3}$, which has been known as a carcinogenic compound.

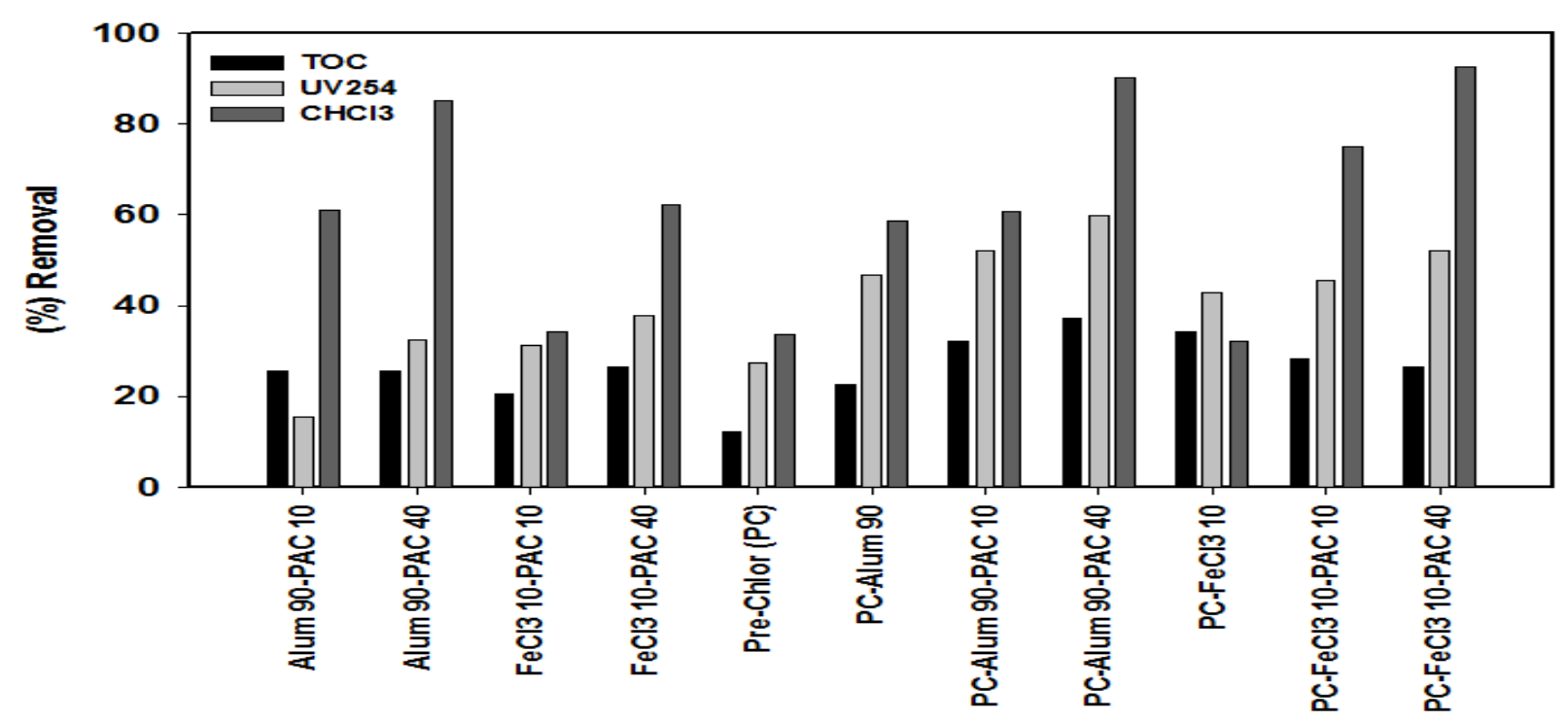

Fig.-1: Performance of Various Treatments in removing TOC, $\mathrm{UV}_{254}$ and $\mathrm{ChCl}_{3}$ Concentration

Pre-chlorination could reduce organic matters because the hypochlorite (hydrolysis of chlorine in the water) oxidized the layer of organic matters to the smallest weight molecule or transformation aromatic. ${ }^{11,13,14}$ It is supported by decreasing $\mathrm{UV}_{254}$. Chlorine reacts strongly with donating groups of electron such as $-\mathrm{OH}$, - OR, $-\mathrm{NH}_{2}$, - $\mathrm{R}$, phenol to activate the aromatic ring and causing THMs. ${ }^{13}$ In addition, the adsorption process could enhance organic matter removal, especially with high dosage. In pre-chlorination, comparison between alum with and without PAC presented that PC-alum with a low dosage of PAC (10 ppm) has similar removal of organic matters to PC-alum only. However, coagulant $\mathrm{FeCl}_{3}$ showed gradually increasing the removal of organic matters and $\mathrm{CHCl}_{3}$ under without $\mathrm{PAC}$, with a low dosage of PAC and a high dosage of PAC. This results conjectured that $\mathrm{FeCl}_{3}$ coagulant has an effective performance under different treatment processes, it is consistent with the previous studies. ${ }^{3,4,10,15}$ Natural coagulants have been developed in the previous studies, and it seems have the opportunity to be applied in this study, since natural coagulant is environment-friendly and biodegradable nature in water. In addition, those natural coagulants could be applied as adsorbent as well. ${ }^{16-18}$

\section{Functional Groups Properties of Organic Matters Under Pre-Chlorination, Coagulation and Adsorption}

Figure-2 and Fig.-3 described the FTIR spectra of functional group organic matters in raw and treated water. The functional group dominant in treated water were alcohols, phenols, aromatic amines, amides, alkenes, and halogen. At a wavelength of $3600-3200 \mathrm{~cm}^{-1}$ is identified as functional groups $\mathrm{OH}$ and $\mathrm{NH}$ (alcohols, phenols, and aromatic amines). Amide group and alkenes identified at $1800-1600 \mathrm{~cm}^{-1}$ and $1650-1500 \mathrm{~cm}^{-1}$, whereas halogen groups are known at $650-550 \mathrm{~cm}^{-1}$ and $570-500 \mathrm{~cm}^{-1}$. Fig. -2 presented percentage transmittance of organic matters after pre-chlorination only and coagulation combined with adsorption. The results showed that pre-chlorination caused decreasing transmittance of functional groups $\mathrm{OH}$ and $\mathrm{NH}$ at $3600-3200 \mathrm{~cm}^{-1}$ wavelengths and amide, alkenes groups at $1650-1500 \mathrm{~cm}^{-1}$ wavelength. It 
RASĀYAN J. Chem.

Vol. 12 | No. 4 |2111 - 2115| October - December | 2019

conjectured that pre-chlorination caused the formation of those compounds, which could be precursors of carcinogenic $\mathrm{CHCl}_{3}$. Pre-chlorination could breakdown high molecular weight organic matters into lower molecular weight fractions. ${ }^{10,14}$ Meanwhile, coagulation combined with adsorption could increase the transmittance of all functional groups. It indicated that coagulant and adsorption could interact with organic fractions through its mechanism. Charge neutralization, complexation, sweep coagulation is probably one of the mechanism to remove organic fractions during coagulation, while pore mechanism is the main role in adsorption., ${ }^{9,15}$

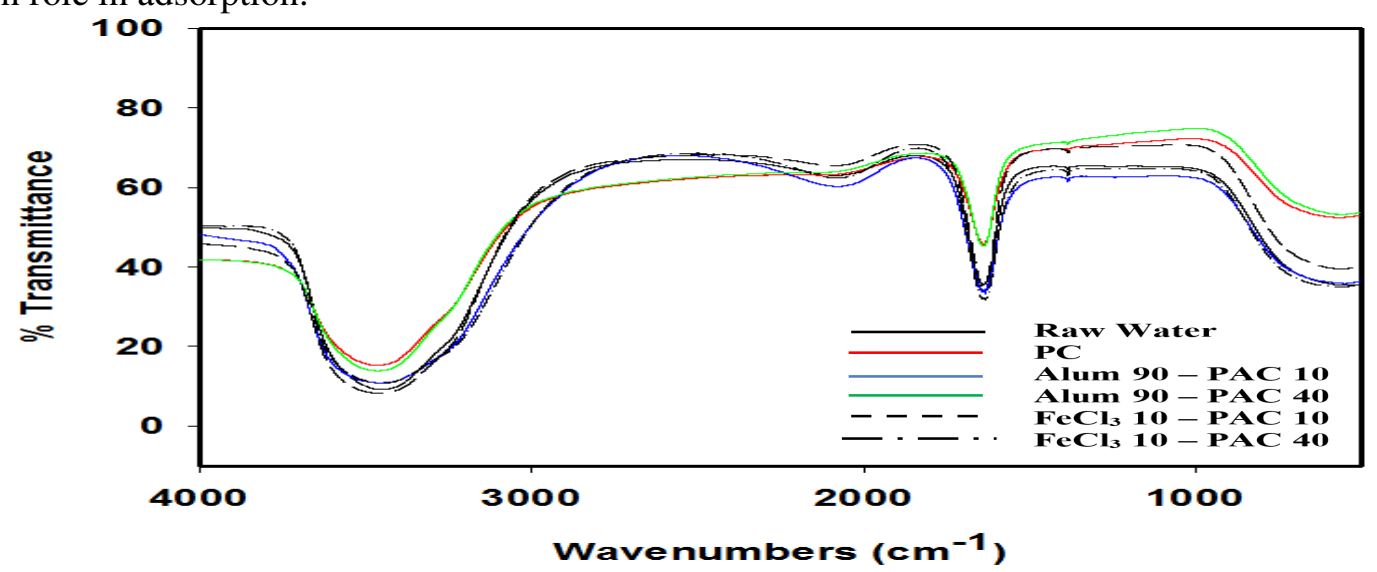

Fig.-2: FTIR Spectrum of Organic Matters in Raw Water and Treated Water using Coagulation-Adsorption

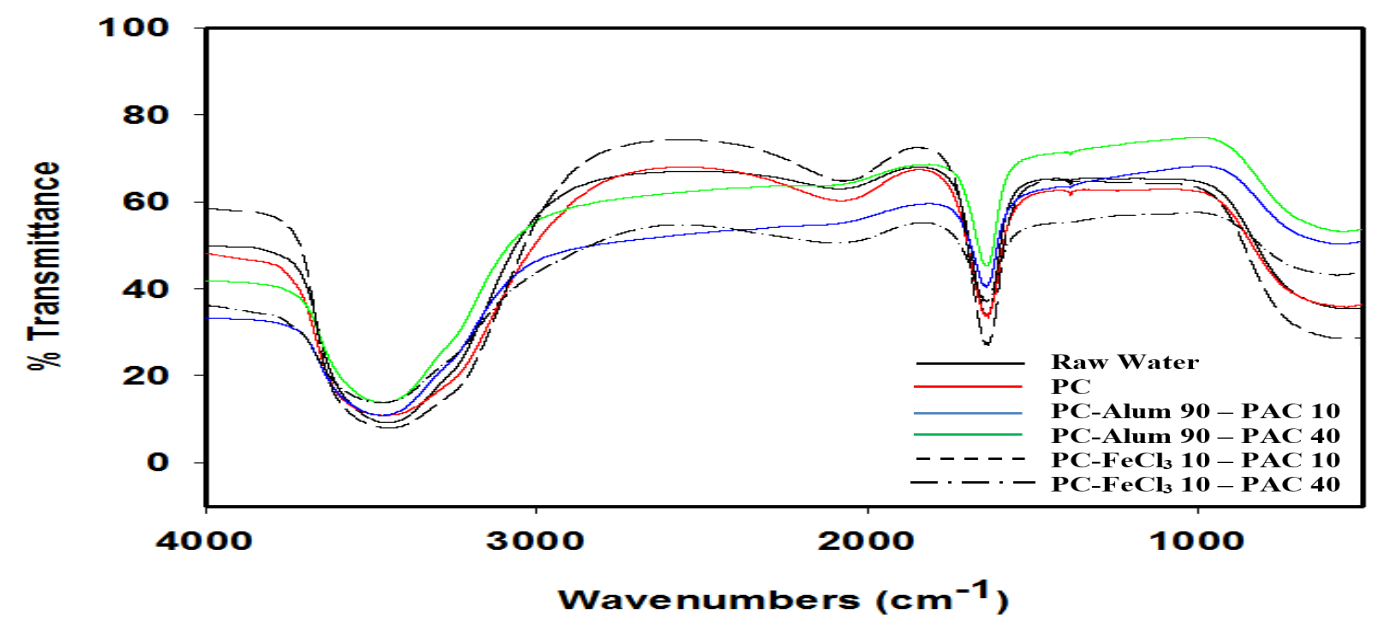

Fig.-3: FTIR Spectrum of Organic Matters in Raw Water and Treated Water using Pre-Chlorination-CoagulationAdsorption

Figure-3 presented percentage transmittance of organic matters after pre-chlorination as pretreatment, followed by coagulation and adsorption. Shortly, the mechanism of organic fractions removal is almost similar to the previous experiment. The results showed that pre-chlorination caused decreasing transmittance of functional groups $\mathrm{OH}$ and $\mathrm{NH}$ at $3600-3200 \mathrm{~cm}^{-1}$ wavelengths. It conjectured that prechlorination caused the formation of those compounds, which could be precursors of carcinogenic $\mathrm{CHCl}_{3}$, even those functional groups existed after coagulation and adsorption. Pre-chlorination could breakdown high molecular weight organic matters into lower molecular weight fractions. ${ }^{10,14}$ It seems that the formed lower molecular weight fractions is a kind of non-aromatic, and hydrophilic compounds, which is difficult to be removed through coagulation and adsorption. The highest percent of transmittance halogen was $39.43 \%$ at a wavelength of $557.39 \mathrm{~cm}^{-1}$. The number of halogen groups shows the presence of THMs in the water. THMs are halogen-substituted single carbon mixtures with general formula $\mathrm{CHX}_{3}$ while $\mathrm{X}$ can represent halogen $\mathrm{F}, \mathrm{Cl}, \mathrm{Br}$, I or another combination. Enhanced coagulation-adsorption could remove NOM and be implemented as an alternative method to reduce and control NOM and THMs in water. 
RASĀYAN J. Chem.

Vol. 12 | No. 4 |2111 - 2115| October - December | 2019

\section{CONCLUSION}

According to the treatment process, $\mathrm{UV}_{254}$ removal is higher than TOC removal. Removal of carcinogenic $\mathrm{CHCl}_{3}$ shows a higher removal along with $\mathrm{UV}_{254}$ removal. It seems that aromatic compounds are organic precursors of $\mathrm{CHCl}_{3}$ formation. Pre-chlorination as pretreatment could enhance coagulation-adsorption for controlling the formation of a carcinogenic compounds, such as trihalomethanes. The addition of adsorption could remove more trihalomethanes formation potential precursors than coagulation only. Organic matter measurement has consistency results with FTIR measurement. Sustainability of prechlorination could be considered as pretreatment in order to remove the carcinogenic compound. However, for future work, a different kind of pre-oxidant could be compared with pre-chlorination to see which pretreatment will generate lower disinfectant by-products. This similar study could be carried out for wastewater treatment, since some of the wastewater treatment have been applying chlorination at the end of treatment.

\section{ACKNOWLEDGMENT}

Author would like to thank the Ministry of Research Technology and Higher Education (Kemenristek Dikti), Indonesia for financial support with Contract No 086/SP2H/LT/DRPM/2019.

\section{REFERENCES}

1. I. Kristiana, C. Joll and A. Heitz, Chemosphere, 83, 661 (2011), DOI:10.1016/j.chemosphere.2011.02.017

2. S.D. Richardson, M.J. Plewa, E.D. Wagner, R. Schoeny and D.M. DeMarini, Mutation Research, 636, 178 (2007), DOI:10.1016/j.mrrev.2007.09.001

3. S.A. Baghoth, Characterizing Natural Organic Matter in Drinking Water Treatment Processes and Trains, UNESCO-IHE Institute, Uganda, p. 12 (2012)

4. A. Matilainen, E.T. Gjessing, E. T. T. Lahtinen, L. Hed, A. Bhatnagar and M. Sillanpää, Chemosphere, 83, 1431 (2011), DOI:10.1016/j.chemosphere.2011.01.018

5. M. Sillanpää, M.C. Ncibi, A. Matilainen and M. Vepsäläinen, Chemosphere, 190, 54 (2018), DOI:10.1016/j.chemosphere.2017.09.113

6. H. Yamamura, K. Kimura and Y. Watanabe, Environmental Science and Technology, 41, 6789 (2007), DOI:10.1021/es0629054

7. S.W. Krasner, H.S. Weinberg, S.D. Richardson, S.J. Pastor, R. Chinn, M.J. Sclimenti, G.D. Onstad and A.D. Thruston, Environmental Science and Technology, 40, 7176 (2006), DOI:10.1021/es060353j

8. A. Bhatnagar and M. Sillanpää, Chemosphere, 166, $500 \quad$ (2017), DOI:10.1016/j.chemosphere.2016.09.098

9. V. Uyak, S. Yavuz, I. Toroz, S. Ozaydin and E.A. Genceli, Desalination, 216, 335 (2007), DOI: 10.1016/j.desal.2006.11.026

10. E.N. Hidayah, Y.C. Chou and H.H. Yeh, Journal of Environmental Science and Health Part A, 52 (4), 391 (2017), DOI:10.1080/10934529.2016.1262607

11. E.N. Hidayah and O.H. Cahyonugroho, Pollution Research, 38 (1), (2019)

12. APHA, AWWA and WEF. Standard Methods for the Examination of Water and Wastewaters (2012)

13. D. Reckhow and P.L. Singer, Water Quality \& Treatment: A Handbook on Drinking Water, AWWA, (2011)

14. P. Xie, Y. Chen, J. Ma, X. Zhang, J. Zou and Z. Wang, Chemosphere, 155, 555 (2016), DOI:10.1016/j.chemosphere.2016.04.003

15. O.H. Cahyonugroho and E.N. Hidayah, Journal of Physics, 953, 2 (2018), DOI:10.1088/17426596/953/1/012217

16. S. Ramesh, J.S. Sudarsan and M. Jothilingam, Rasayan Journal of Chemistry, 9, 3 (2016)

17. C. Sumithra and Karthikeyan, Rasayan Journal of Chemistry, 7, 149 (2014)

18. S. Karthikeyan, K. Sakthivel and C. Kannan, Rasayan Journal of Chemistry, 4, 519 (2011)

[RJC-5472/2019] 